\title{
Prediction of Strain Limits via the Marciniak-Kuczynski Model and a Novel Semi-Empirical Forming Limit Diagram Model for Dual-Phase DP600 Advanced High Strength Steel
}

\author{
Ilyas Kacar1,* - Fahrettin Ozturk ${ }^{2,3}$ - Serkan Toros ${ }^{1}$ - Suleyman Kilic ${ }^{4}$ \\ 1 Nigde Ömer Halisdemir University, Turkey \\ 2 Turkish Aerospace Industries, Inc., Turkey \\ ${ }^{3}$ Ankara Yıldırım Beyazıt University, Turkey \\ ${ }^{4}$ Kirsehir Ahi Evran University, Turkey
}

The prediction capability of a forming limiting diagram (FLD) depends on how the yield strength and anisotropy coefficients evolve during the plastic deformation of sheet metals. The FLD predictions are carried out via the Marciniak-Kuczynski (M-K) criterion with anisotropic yield functions for DP600 steel of various thicknesses. Then, a novel semi-empirical FLD criterion is proposed, and prediction capabilities of the criterion are tested with different yield criteria. The results show that the yield functions are very sensitive to anisotropic evolution. Thus, while the FLD curves from the M-K model and the proposed model are not the same for each thickness, the proposed model has better prediction than the M-K model.

Keywords: DP600, anisotropy, yield criterion, forming limit diagram, M-K failure criterion

\section{Highlights}

- $\quad$ The most popular failure criterion, the Marciniak-Kuczynski, is compared to a novel semi-empirical failure criterion presented for sheet metals.

- $\quad$ The most appropriate and conservative yield function among anisotropic functions is the YLD2000-2d to be able to use with the failure criterion for DP600 sheet steel.

- $\quad$ The YLD2000-2d model parameters are presented for DP600 steel.

- $\quad$ Prediction capabilities for strain limits are presented on forming limit curves.

\section{INTRODUCTION}

Some strategies on weight reduction have been developed for vehicles in transportation, one of which is to be able to use a thinner body without sacrificing strength requirements by using stronger sheet metal, known as advanced high strength steel (AHSS), which can provide weight saving due to its higher strength leading to thinner and lighter bodies. Therefore, its use in automobile body parts has been increased tremendously [1] to [3]. In AHSS, dualphase (DP) steels are manufactured by holding low carbon steel at the austenite temperature for a while and then quenching. They include both ferrite and martensite, which come from the cooling of unstable austenite [4]. AHSSs have been increasingly used in automotive structural components, such as floor panels [5] and the trunk lid [6] due to their corrosion resistance, toughness, and high resistance to impact. However, it should be taken into consideration that carbon and nitrogen alloying elements decrease their formability. Numerous research studies have been carried out to enhance their mechanical behaviour, especially formability [7] to [11]. The determination of formability limitations is one of the requirements to achieve safer forming for sheet metals [12].

Using forming limit curves is one of the methods to determine necking initiation during deformation. These curves are based on stress (forming limit stress diagram (FLSD)) or strain (forming limit diagram (FLD)). This study focuses on the FLD and determines the formability limit and safe zone of the sheet material under various deforming conditions. It is also an efficient tool for diagnosing manufacturing defects. Sheet metals have their own specific FLD curves. Fig. 1 shows a typical FLD.

The FLD was introduced by Keeler and Backhofen [13], and Goodwin [14] developed their application to sheet metal forming problems. Although today an FLD consists of two curves known as right-left side curves, Keeler and Backhofen [13] first developed the right side of the FLD (positive minor strain side). Goodwin [14] extended the curve to the left side (negative minor strain side). Forming limit curves are determined by using a failure criterion based on necking. An accurate determination of neck initiation and propagation is not an easy task in sheet metals. Various deformation processes from uniaxial to biaxial loadings may 
cause different strain combinations. Also, material anisotropy has a significant effect on the strain pattern besides loading conditions [15] to [17]. Swift [18] and Hill [19] developed a failure criterion based on instability analysis to determine necking [18] and [19]. While Swift's criterion takes care of the maximum force's direction to determine diffuse necking, Hill's criterion, which is especially suitable for anisotropy in sheet metals, is based on discontinuity to determine localized necking. While the first has the ability to construct just the right-hand side of the FLD, which is useful when strains at all directions are positive, the other one constructs just its left-hand side. Thus, it is quite possible to take different results depending on the criterion. In recent years, one of the criteria is presented in the finite element codes to determine the FLD [20].

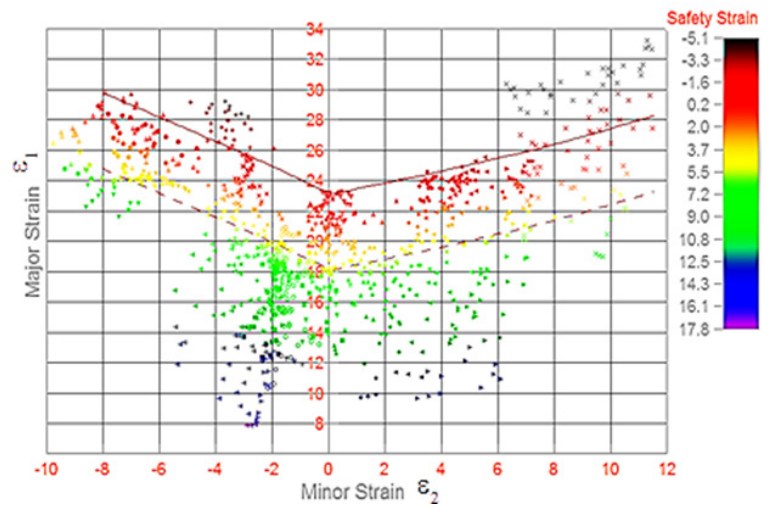

Fig. 1. An example FLD from ASAME software

Marciniak and Kuczynski [21] presented another instability criterion, known as the M-K model, based on force equilibrium. It can take into account geometric imperfection or inhomogeneity. Banabic et al. [22] compared their model to a maximum force criterion [23], diffusion based criterion [18], and the localized necking approach [19] to predict the FLD for a stamping process with a linear strain path by combining the M-K criterion and their orthotropic yield function, known as $\mathrm{BBC} 2003$ [24]. Later, it was developed as BBC2008 [25]. For a deep drawing simulation, the onset of necking was predicted, and yield surfaces were obtained via the $\mathrm{M}-\mathrm{K}$ criterion [26]. Many comparative studies were collected on the FLD prediction [27]. As a result, it is seen that the $\mathrm{M}-\mathrm{K}$ model is a preferred failure criterion due to its closer results to experimental data.

The present study shows FLD predictions from combined models of the M-K with some anisotropic yield criteria. The curves were evaluated through experimental data collected from DP600 steel. The most appropriate criterion to represent the anisotropy properly was determined. The model and its curves show its applicability and accuracy on various deformation types for DP600.

\section{MATERIAL AND METHOD}

DP steels are characterized by their microstructure where hard martensite grains are dispersed. Martensite grains provide high strength in the soft and ductile structure of the ferritic matrix. The strength is adjusted by the amount of martensite and carbon content. In this study, DP600 sheet was examined by means of uniaxial tensile tests with a $100 \mathrm{kN}$ tensile test machine. Elongation was determined by its extensometer with two cameras. Specimens of $0.8 \mathrm{~mm}$ thickness were prepared from rolling in the diagonal (DD) and transverse (TD) directions, according to the ASTM E8 / E8 standard [28]. The strain rate was $0.0083 \mathrm{~s}^{-1}$. Initial yield point $\left(\sigma_{0}\right)$, anisotropy coefficients ( $r$-values), strength coefficient $(K)$, and, hardening exponent $(n)$ were obtained to use as plasticity model parameters explained in the subsequent sections in detail [29]. The results were given in Table 1. Tensile curves were obtained, as seen in Fig. 2. Even small discrepancies were seen, all curves had similar shapes. Although the yield strength was approximately the same for all, the ultimate tensile strength and total elongations were different.

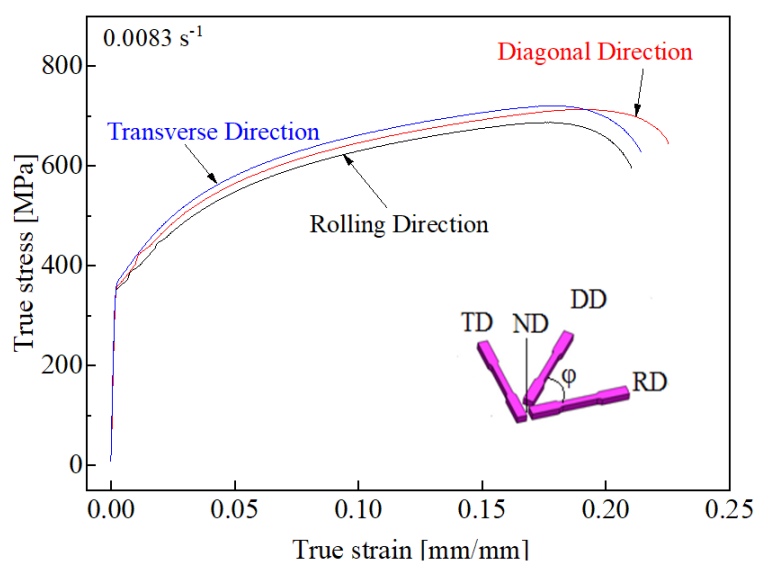

Fig. 2. Tensile properties at different orientations for DP600 steel

An experimental FLD curve was drawn using the out-of-plane formability test with $0.8 \mathrm{~mm}$ sheet thickness. The values for $1.6 \mathrm{~mm}$ and $2 \mathrm{~mm}$ were used from the literature [30]. The tensile test was done only for the thickness of $0.8 \mathrm{~mm}$ because mechanical properties were independent on the thickness. The experiments were repeated three times on a 
double-action special press machine with a $100 \mathrm{~mm}$ hemispherical punch. Before deformation, $2.5 \mathrm{~mm}$ $\times 2.5 \mathrm{~mm}$ square grids were printed on the sample surface. After deformation, strains on the deformed grids were detected by an image processing software ASAME $^{\odot}$. The results were shown in Fig. 3. An offsetting procedure to reduce the size of the safe zone on the experimental FLD curve was applied as dashed lines. It increases the reliability as depicted in the Fig. 3.

Table 1. Tensile test results for DP600 sheet steel

\begin{tabular}{lcccc}
\hline Direction & $\begin{array}{c}\text { Yield } \\
\text { strength } \\
{[\mathrm{MPa}]}\end{array}$ & $r$-value & $\begin{array}{c}\text { Hardening } \\
\text { exponent, } \\
n\end{array}$ & $\begin{array}{c}\text { Strength coefficient, } \\
K \\
{[\mathrm{MPa}]}\end{array}$ \\
\hline $\mathrm{RD}\left(0^{\circ}\right)$ & 355 & 0.89 & 0.194 & $979.46\left(R^{2}=0.996\right)$ \\
\hline $\mathrm{DD}\left(45^{\circ}\right)$ & 362 & 0.85 & 0.191 & $994.25\left(R^{2}=0.996\right)$ \\
\hline $\mathrm{TD}\left(90^{\circ}\right)$ & 371 & 1.12 & 0.188 & $1014.44\left(R^{2}=0.997\right)$ \\
\hline
\end{tabular}

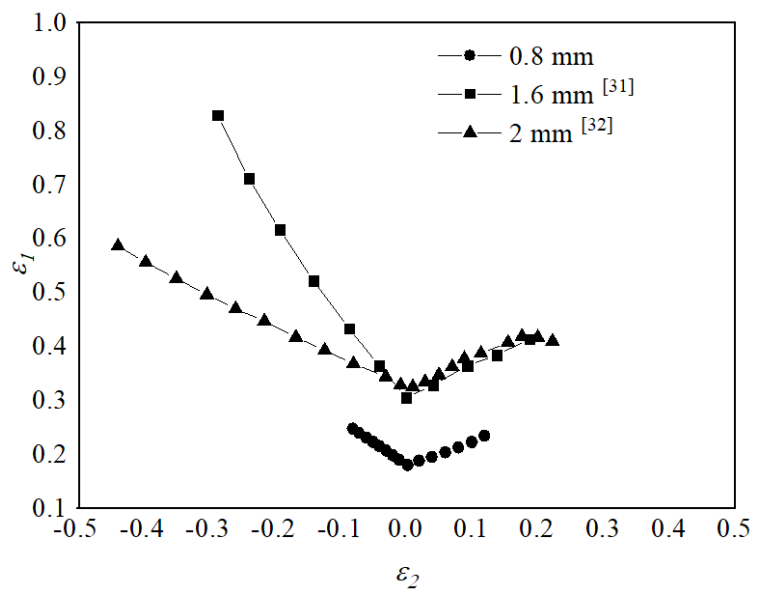

Fig. 3. FLDs determined for various thicknesses (1.6 mm: [31], $2 \mathrm{~mm}:$ [32])

While the area under the curves of the FLDs depicts the safe zone where the dashed line limits the safer zone, its size gives the material's forming ability. The more area under the FLD curve leads to a bigger safe zone for deformation. Strain limits depend on thickness and strain signs. While the bigger thickness leads to the more formability when the strain $\varepsilon_{2}$ has a positive sign, the formability decreases in the negative region contrary to expectations, especially for thicknesses $1.6 \mathrm{~mm}$ or $2 \mathrm{~mm}$. Experiments with the $1.6 \mathrm{~mm}$ sample were carried out under in-plane deformation conditions while the other two were tested under out-of-plane conditions. The strain limit depends on the test method performed in-plane or outof-plane deformation. Thus, a safety margin is used to eliminate the difference in practice.

\section{YIELD CRITERIA}

A plasticity model consists of a yield criterion to define an elastic to the plastic boundary, a hardening rule to model the evolution of this boundary during plastic deformation, and a flow rule to define plastic strain increment vector. Also, a failure criterion can be used in the case of failure estimates. The yield criterion's function produces one equivalent stress from stress components. In this study, the plasticity models were derived by using the Hill48, the Barlat89, and the YLD2000-2d functions.

\subsection{Hill48}

A yield formula of the quadratic Hill48 was given in Eq. (1) [33]:

$$
\begin{aligned}
2 f\left(\sigma_{i j}\right) & =F\left(\sigma_{y}-\sigma_{z}\right)^{2}+G\left(\sigma_{z}-\sigma_{x}\right)^{2}+ \\
& H\left(\sigma_{x}-\sigma_{y}\right)^{2}+2 L \tau_{y z}^{2}+2 M \tau_{z x}^{2}+2 N \tau_{x y}^{2}=1,(1)
\end{aligned}
$$

where $x, y, z$ axes are mutually orthogonal. Its coefficients represent the anisotropic behaviour. The coefficients $N, M, L, H, G$, and $F$ can be calculated by using anisotropy coefficients $r_{0}, r_{45}, r_{90}$, as in Eq. (2).

$$
\begin{array}{ll}
F=\frac{r_{0}}{r_{90}\left(1+r_{90}\right)}, & G=\frac{1}{\left(1+r_{0}\right)}, \\
H=\frac{r_{0}}{\left(1+r_{0}\right)}, & N=\frac{\left(r_{0}+r_{90}\right)+\left(1+r_{45}\right)}{2 r_{90}\left(1+r_{0}\right)} .
\end{array}
$$

\subsection{Barlat89}

Another widely used anisotropic yield function in sheet metal deformation simulations was proposed by Barlat and Lian [34] (denoted as the Barlat89):

$$
\varnothing=a\left|K_{1}+K_{2}\right|^{M}+b\left|K_{1}-K_{2}\right|^{M}+c\left|2 K_{2}\right|^{M}=2 \bar{\sigma}^{M},
$$

where $\bar{\sigma}$ is the equivalent stress. $M=6$ or 8 in the case of body-centred cubic or face-centred cubic microstructure. $K_{1}$ and $K_{2}$ are two invariants for stress tensor seen in Eqs. (4) to (6). Its coefficients; $p, a, c, h$ characterize the anisotropic behaviour.

$$
\begin{gathered}
K_{1}=\frac{\sigma_{x}+h \sigma_{y}}{2}, \quad K_{2}=\sqrt{\left(\frac{\sigma_{x}+h \sigma_{y}}{2}\right)^{2}+p^{2}} \tau_{x y}^{2}, \\
a=2-c=2-2 \sqrt{\frac{r_{0}}{1+r_{0}} \frac{r_{90}}{1+r_{90}}},
\end{gathered}
$$




$$
h=\sqrt{\frac{r_{0}}{1+r_{0}}} \frac{1+r_{90}}{r_{90}}, \quad p=\frac{\bar{\sigma}^{M}}{\tau_{s 1}} \sqrt{\left(\frac{2}{2 a+2^{M} c}\right)},
$$

where $h, c$, and $a$ can be computed based on $r$-values. However, $p$ cannot be calculated directly but using some ways explained in [34]. $\tau_{s 1}$ is yield point from shear stress test and $\tau_{s 1}=\sigma_{x y}$ while $\sigma_{x x}=\sigma_{y y}=0$.

\subsection{YLD2000-2d}

Barlat et al. [35] presented another function known as the YLD2000-2d, which is more powerful to represent the anisotropy. It is described as follows:

$$
f^{\frac{1}{M}}=\left\{\frac{\varnothing}{2}\right\}^{\frac{1}{M}}=\bar{\sigma}
$$

where $\bar{\sigma}$ is the equivalent stress and

$$
\varnothing=\left|\tilde{S}_{1}^{\prime}-\tilde{S}_{2}^{\prime}\right|^{M}+\left|\tilde{S}_{1}^{\prime \prime}+2 \tilde{S}_{2}^{\prime \prime}\right|^{M}+\left|2 \tilde{S}_{1}^{\prime \prime}+\tilde{S}_{2}^{\prime \prime}\right|^{M},
$$

where $M$ is an exponent the same that of Barlat89 [24]. $\tilde{S}_{k}^{\prime}$ and $\tilde{S}_{k}^{\prime \prime}(k=1,2)$ are principal stresses in the transformed domain when $\tilde{s}^{\prime}$ and $\tilde{s}^{\prime \prime}$ are stress deviators. Transformations are linear based on $\tilde{s}=C S$.

$$
\begin{gathered}
\tilde{s}^{\prime}=C^{\prime} S=L^{\prime} \sigma, \\
\tilde{s}^{\prime \prime}=C^{\prime \prime} S=L^{\prime \prime} \sigma,
\end{gathered}
$$

where $C^{\prime}$ and $C^{\prime \prime}$ are matrices providing transformations. The ' and "superscripts mean two different transformations. $\sigma$ shows the stress state. $T$ is a matrix including constants. The explicit forms of $L^{\prime}$ and $L^{\prime \prime}$ matrices are given in Eqs. (11) and (12).

$$
\begin{gathered}
{\left[\begin{array}{l}
L_{11}^{\prime} \\
L_{12}^{\prime} \\
L_{21}^{\prime} \\
L_{22}^{\prime} \\
L_{66}^{\prime}
\end{array}\right]=\left[\begin{array}{ccc}
2 / 3 & 0 & 0 \\
-1 / 3 & 0 & 0 \\
0 & -1 / 3 & 0 \\
0 & 2 / 3 & 0 \\
0 & 0 & 1
\end{array}\right]\left[\begin{array}{l}
\alpha_{1} \\
\alpha_{2} \\
\alpha_{7}
\end{array}\right],} \\
{\left[\begin{array}{l}
L_{11}^{\prime \prime} \\
L_{12}^{\prime \prime} \\
L_{21}^{\prime \prime} \\
L_{22}^{\prime \prime} \\
L_{66}^{\prime \prime}
\end{array}\right]=\left[\begin{array}{ccccc}
-2 & 2 & 8 & -2 & 0 \\
1 & -4 & -4 & 4 & 0 \\
4 & -4 & -4 & 1 & 0 \\
-2 & 8 & 2 & -2 & 0 \\
0 & 0 & 0 & 0 & 1
\end{array}\right]\left[\begin{array}{l}
\alpha_{3} \\
\alpha_{4} \\
\alpha_{5} \\
\alpha_{6} \\
\alpha_{8}
\end{array}\right],}
\end{gathered}
$$

where $\alpha_{1}$ to $\alpha_{8}$ are the YLD2000-2d function's parameters providing anisotropic effects. No direct formula to calculate them exists, so an inverse identification technic based on error minimization by referring to experimental yield strengths $\left(\sigma_{0}, \sigma_{45}\right.$, $\left.\sigma_{90}, \sigma_{b}\right)$ and anisotropy coefficients $\left(r_{0}, r_{45}, r_{90}, r_{b}\right)$ are applied to determine them. This method was explained in detail in [36]. To determine the YLD2000-2d yield function model's parameters, theoretical calculation of anisotropies and yield stresses, at different orientation angles were used. In the theoretical calculation of the biaxial stress and similarly in biaxial anisotropy calculation, it was assumed that $\sigma_{b}=\sigma_{11}=\sigma_{22}$. Equibiaxial yield strength $\sigma_{b}=379.85 \mathrm{MPa}$ was determined via the bulge test and biaxial anisotropy as $r_{b}=0.735$ is then determined with the help of hole expansion test [37].

\subsection{Application of the M-K Failure Criterion}

This criterion assumes that the sheet metal includes a pre-existing thickness imperfection on the surface lying along the rolling direction. An imperfection factor is defined as $f_{0}=\left(t_{0}^{a} / t_{0}^{b}\right)$ where $t$ defines thickness. The imperfection free zone and imperfection's zone are denoted by ' $a$ ' and ' $b$ ' superscripts, respectively. Subscript 0 means anything at the beginning. If any biaxial stress increment is applied to a sheet metal, it leads to a strain increment in $a$ and $b$ sections. Necking initiates if the strain increment in section $b$ is ten times higher than that of section $a$ [38] to [41]. Force exerted in $a$ and $b$ must be in balance during loading, as explained in Eq. (13).

$$
F_{n t}^{a}=F_{n t}^{b}, \quad F_{n n}^{a}=F_{n n}^{b},
$$

where $F$ is the force and $n, t$ shows the normal and tangential axes. Similarly, both equations can be rewritten in terms of stresses as in Eq. (14).

$$
\sigma_{n t}^{a} \cdot t_{0}^{a} e^{\varepsilon_{3}^{a}}=\sigma_{n t}^{b} \cdot t_{0}^{b} e^{\varepsilon_{3}^{b}}, \quad \sigma_{n n}^{a} \cdot t_{0}^{a} e^{\varepsilon_{3}^{a}}=\sigma_{n n}^{b} \cdot t_{0}^{b} e^{\varepsilon_{3}^{b}},
$$

where $t_{0}$ is initial sheet thickness. $\sigma_{n n}$ and $\sigma_{n t}$ are normal and tangential stresses. The strain component exerted through thickness in the normal axis is $\varepsilon_{3}$. The imperfection factor $f$ can be generalized as in Eq. (15).

$$
f=f_{0} \cdot e^{\left(\varepsilon_{3}^{b}-\varepsilon_{3}^{a}\right)},
$$

where $f_{0}$ is initial imperfection factor. $\varepsilon_{3}$ can be determined by using incompressibility condition [42]. The stress components $\sigma_{n n}^{b}, \sigma_{t t}^{b}, \sigma_{n t}^{b}$, and effective strain increment $d \bar{\varepsilon}^{b}$ can be solved by means of simultaneous solution of four equations in Eq. (16). 


$$
\begin{aligned}
& F_{1}=\frac{d \varepsilon_{n n}^{b} \sigma_{n n}^{b}+d \varepsilon_{t t}^{b} \sigma_{t t}^{b}+d \varepsilon_{n t}^{b} \sigma_{n t}^{b}}{d \bar{\varepsilon}_{b} \bar{\sigma}_{Y}}-1=0, \\
& F_{2}=\frac{d \varepsilon_{t t}^{b}}{d \varepsilon_{t t}^{a}}-1=0, \\
& F_{3}=f \frac{\sigma_{n n}^{b}}{\sigma_{n n}^{a}}-1=0, \\
& F_{4}=f \frac{\sigma_{n t}^{b}}{\sigma_{n t}^{a}}-1=0 .
\end{aligned}
$$

Although these equations depend on the groove angle, the M-K model can be used without the groove angle by following the flowchart in [43]. The flowchart has been followed in this study. The $f_{0}$ parameter of the M-K model was taken as 0.995 . The other parameters of the model depend on the strain and $f_{0}$.

\subsection{The Proposed Failure Criterion}

The FLD consists of two curves and one intersecting point depending on three deformation modes such as uniaxial, biaxial, and plane strain deformations. While uniaxial strains give points on the curve in the left-hand side, biaxial strains give points on the other curve in the right-hand side with respect to zero strain point in the horizontal axis. Both curves are intersected at a point corresponding to zero strain in the horizontal axis leading to one strain component, which causes to plane strain deformation. In the study, a novel semi-empirical FLD model was proposed, which was created via regression analysis of the experimentally obtained FLD diagrams of the several materials that were obtained by the other researches of the authors. During the modelling of the FLDs, the general mechanical properties that affect the FLDs of the materials were defined. As is well-known from the experiences and literature, the thickness and anisotropic features of the materials are the main characters that can change the FLDs. During the fitting analysis of the simple mathematical formulations, the constants were then constrained with the given experimental properties. The model consists of three formulas corresponding two curves and one intersecting point. The formulas are based on normal anisotropy $r$, biaxial anisotropy $r_{b}$, sheet thickness $t$, and strains as seen in Eq. (17).

$$
\varepsilon_{1}=\left\{\begin{array}{l}
-r \varepsilon_{2}+F L D_{0}, \quad \varepsilon_{2}<0 \\
-r_{b} \varepsilon_{2}^{r_{b} / 2}+F L D_{0}, \quad \varepsilon_{2}>0 . \\
\text { where } F L D_{0}=\varepsilon_{\text {eng } \%} t^{3 n}
\end{array}\right.
$$

$F L D_{0}$ is the major strain at the point corresponding zero strain in the horizontal axis $\left(\varepsilon_{2}=0\right)$. It depends on the engineering strain percentage $\varepsilon_{\text {eng } \% \text {, sheet }}$ thickness $t$ and hardening exponent $n$. Although there are many experiment types to determine the biaxial anisotropy, such as disk compression test [44], biaxial stretching test [45], or hole expansion test [46], it can also be calculated by using a flow rule, as in Eqs. (18) to (20), which gives the strain increment relation.

$$
\begin{gathered}
d \varepsilon_{11}=d \lambda \frac{\partial f}{\partial \sigma_{11}}=d \bar{\varepsilon} \frac{\partial \bar{\sigma}}{\partial \sigma_{11}}, \\
d \varepsilon_{22}=d \lambda \frac{\partial f}{\partial \sigma_{22}}=d \bar{\varepsilon} \frac{\partial \bar{\sigma}}{\partial \sigma_{22}}, \\
r_{b}=\frac{\frac{\partial \bar{\sigma}}{\partial \sigma_{22}}}{\frac{\partial \bar{\sigma}}{\partial \sigma_{11}}}
\end{gathered}
$$

where $\lambda$ is a multiplier, $d \varepsilon$ gives true plastic strain increment. $f$ is a scalar function defining "plastic potential". When the plastic potential function is $\bar{\sigma}$, this formula becomes the associated flow rule. $\sigma_{11}$ and $\sigma_{22}$ are plane stress states at the longitudinal and transverse axes with respect to the rolling axis.

\subsection{Hardening Rule}

An isotropic hardening rule presented by Hollomon as in Eq. (21) is used [47]. Thus the evolution on the stress $\sigma_{h}$ due to hardening during plastic deformation is obtained.

$$
\sigma_{h}=K \varepsilon^{n},
$$

where $K$ is the strength coefficient, $n$ stands for the strain-hardening exponent, and $h$ means the isotropic hardening function. These are determined from curve fitting of tensile data.

\section{RESULT AND DISCUSSIONS}

While the parameters of the Hill48 and the Barlat89 can be determined from $r$-values, the YLD2000-2d's coefficients were determined by optimization based on the nonlinear least-squares method. Kılıç et al. [48] explained an application of this optimization method in detail. The coefficients were calculated as in Table 2 for various thicknesses.

In any plastic deformation process, it is expected that the plasticity model should give the yield point 
Table 2. Coefficients of the yield functions

\begin{tabular}{|c|c|c|c|c|c|c|c|c|c|}
\hline \multirow{4}{*}{ Hill48 } & Thickness & \multicolumn{2}{|c|}{$F$} & \multicolumn{2}{|c|}{$G$} & \multicolumn{2}{|c|}{$H$} & \multicolumn{2}{|c|}{$N$} \\
\hline & $0.8 \mathrm{~mm}$ & \multicolumn{2}{|c|}{0.4204} & \multicolumn{2}{|c|}{0.5291} & \multicolumn{2}{|c|}{0.4709} & \multicolumn{2}{|c|}{1.2819} \\
\hline & $1.6 \mathrm{~mm}$ & \multicolumn{2}{|c|}{0.46} & \multicolumn{2}{|c|}{0.5754} & \multicolumn{2}{|c|}{0.4246} & \multicolumn{2}{|c|}{1.5304} \\
\hline & $2 \mathrm{~mm}$ & \multicolumn{2}{|c|}{0.4035} & \multicolumn{2}{|c|}{0.5977} & \multicolumn{2}{|c|}{0.4023} & \multicolumn{2}{|c|}{1.5369} \\
\hline \multirow{4}{*}{ Barlat89 } & Thickness & \multicolumn{2}{|c|}{$a$} & \multicolumn{2}{|c|}{$c$} & \multicolumn{2}{|c|}{$h$} & \multicolumn{2}{|c|}{$p$} \\
\hline & $0.8 \mathrm{~mm}$ & \multicolumn{2}{|c|}{1.0024} & \multicolumn{2}{|c|}{0.9976} & \multicolumn{2}{|c|}{0.9441} & \multicolumn{2}{|c|}{0.95} \\
\hline & $1.6 \mathrm{~mm}$ & \multicolumn{2}{|c|}{1.0971} & \multicolumn{2}{|c|}{0.9029} & \multicolumn{2}{|c|}{0.9406} & \multicolumn{2}{|c|}{1.015} \\
\hline & $2 \mathrm{~mm}$ & \multicolumn{2}{|c|}{1.1037} & \multicolumn{2}{|c|}{0.8963} & \multicolumn{2}{|c|}{0.8979} & \multicolumn{2}{|c|}{1.015} \\
\hline \multirow{4}{*}{ YLD2000-2d } & Thickness & $\alpha_{1}$ & $\alpha_{2}$ & $\alpha_{3}$ & $\alpha_{4}$ & $\alpha_{5}$ & $\alpha_{6}$ & $\alpha_{7}$ & $\alpha_{8}$ \\
\hline & $0.8 \mathrm{~mm}$ & 1.0221 & 0.9387 & 1.0668 & 0.9766 & 0.9992 & 0.9806 & 0.9719 & 0.9778 \\
\hline & $1.6 \mathrm{~mm}$ & 1.011 & 0.9162 & 1.0651 & 0.9793 & 1.0048 & 0.9653 & 0.9729 & 0.9356 \\
\hline & $2 \mathrm{~mm}$ & 0.98 & 0.9431 & 1.078 & 0.9767 & 1.0075 & 0.951 & 0.9766 & 0.9281 \\
\hline
\end{tabular}

and anisotropy predictions as accurately as possible. Therefore, the model performances were evaluated by their predictions on the yield strength and anisotropy coefficients depending on plane angle $\varphi$. Formulas derived based on plane stress transformations as in Eqs. (22) and (23) [49] were used to estimate the yield points and anisotropies.

$$
\begin{gathered}
\sigma_{\varphi}=\frac{\sigma_{h}}{F_{\varphi}}, \\
r_{\varphi}=\frac{F_{\varphi}}{\frac{\partial \bar{\sigma}}{\partial \sigma_{11}}+\frac{\partial \bar{\sigma}}{\partial \sigma_{22}}}-1,
\end{gathered}
$$

where $F_{\varphi}$ includes trigonometric terms and comes from plane stress transformations. Its terms depend on yield criterion. $\sigma_{h}$ stands for the isotropic hardening rule. $\bar{\sigma}$ is the equivalent stress, which comes from yield criterion. $\sigma_{\varphi}$ is the yield strength and $r_{\varphi}$ is the anisotropy coefficient at any angle $\varphi$ in relation with the rolling direction. Experimental data obtained from the $0.8 \mathrm{~mm}$ DP600 steel sheet were used for comparisons. Figs. 4 and 5 show the prediction curves and experimental points. Stresses were normalized. The best fit to experimental points was given by YLD2000-2d. Its success is based on the criterion including eight parameters to be able to represent the anisotropy.

The yield function's responses were also investigated in the case of thickness variation in Figs. 6 to 8. The YLD2000-2d draws the same shape for all cases. The other two criteria exhibit some small differences when the thickness changes. All criteria predicted the same value for uniaxial tension/ compression points at the rolling direction. The curves from the Hill48 and the Barlat89 criteria exhibited the most deviation when the thickness is $2 \mathrm{~mm}$.
The yield surfaces for all yield criteria were compared when the thickness is $0.8 \mathrm{~mm}$ in Fig. 9. The stresses were predicted the same by all criteria for uniaxial tension/compression cases at rolling and transverse directions. They differed at biaxial and shear deformation regions. The most conservative one was the YLD2000-2d due to its smallest boundary.

FLD curves from the M-K and the proposed failure models were given in Figs. 10 and 11, respectively. Each model consists of the yield criteria and the failure criteria. Three $\mathrm{M}-\mathrm{K}$ failure models, including the Hill48, the Barlat89, and the YLD2000 criteria, were compared to the experimental data for $0.8 \mathrm{~mm}, 1.6 \mathrm{~mm}$, and $2 \mathrm{~mm}$. The responses of the yield functions with the $\mathrm{M}-\mathrm{K}$ failure criterion were investigated for thickness variation in Fig. 8. It is seen that while thickness $<2 \mathrm{~mm}$, the curves from the M-K models combined with the Hill48 or the YLD2000$2 \mathrm{~d}$ were closer to the experimental data. For $2 \mathrm{~mm}$, while the best representation of the right side was

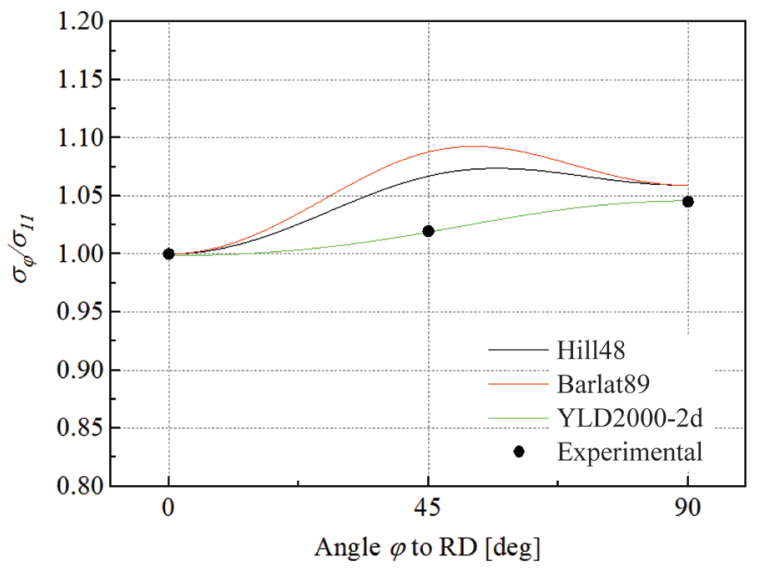

Fig. 4. Yield stress predictions 
done by the models combined with the Hill48 and the YLD20002d, none of them provided a good fit for the left side. The YLD20002d gave conservative predictions on the right side curves for all cases.

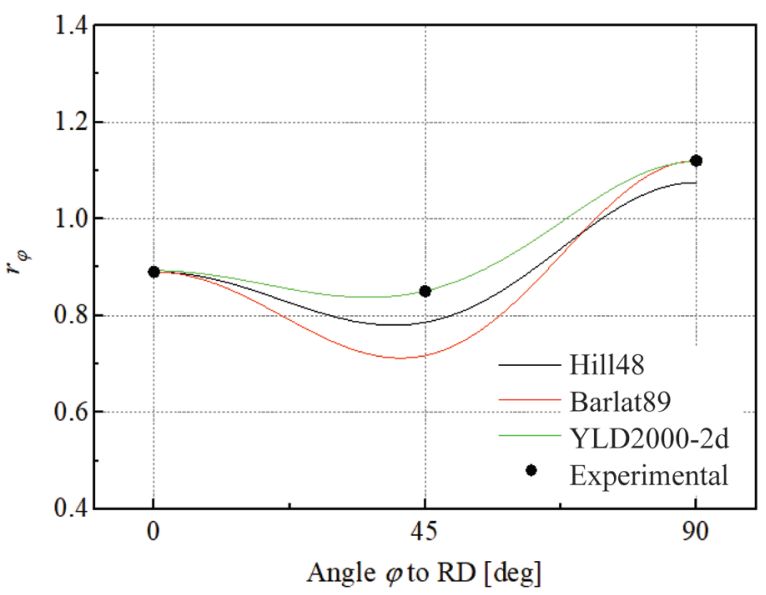

Fig. 5. Anisotropy coefficients prediction

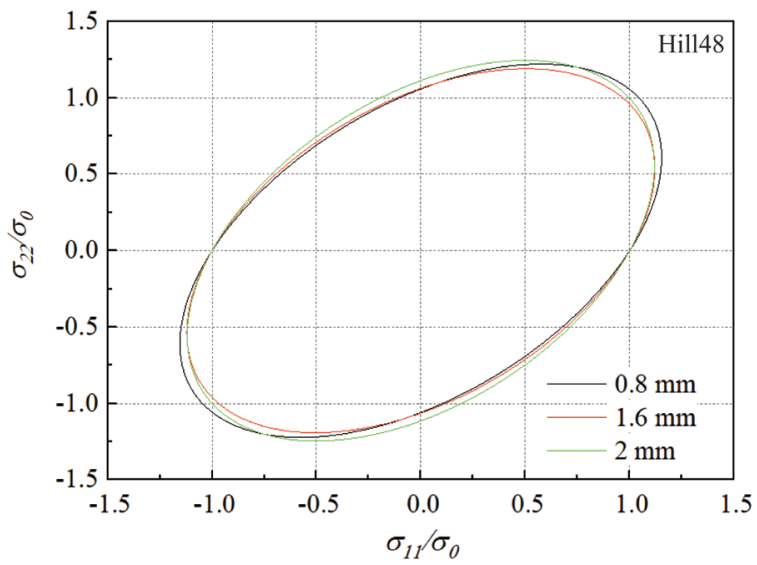

Fig. 6. The yield contours predicted with the Hill-48 for different thicknesses

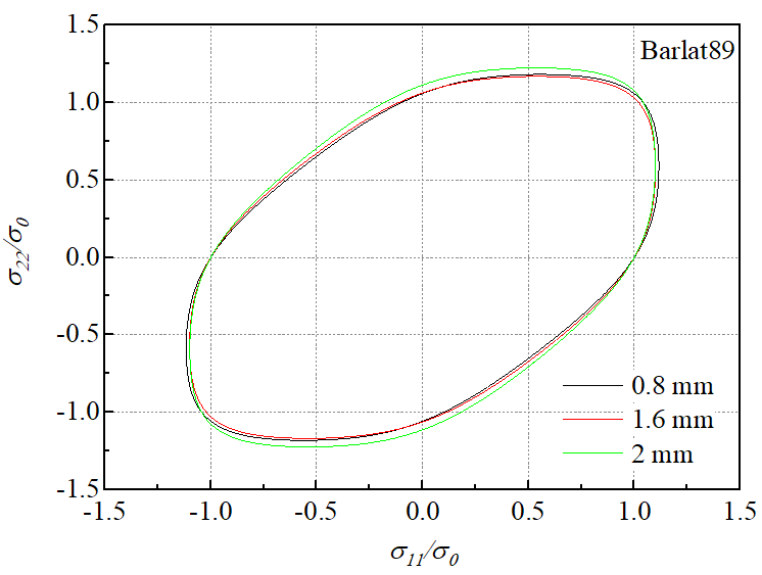

Fig. 7. The yield contours predicted with the Barlat 89 for different thicknesses
In the Fig. 11, the responses of the yield functions from the proposed model were given on the FLD curves. It is seen that the curves are in better agreement for all cases when compared to those from the M-K criterion. The proposed model was easier for calculations. The YLD20002d was more conservative at the right side for all cases.

In Fig. 12, when the YLD2000-2d criterion was used, the FLD curves from the M-K model and the proposed model were presented with the experimental curve. The proposed model was generally more convenient for the experiments.

\section{CONCLUSIONS}

The forming limits were investigated for DP600 steel. Anisotropic yield functions were used with the M-K model and a novel semi-empirical model. Prediction capabilities for strain limits were determined from

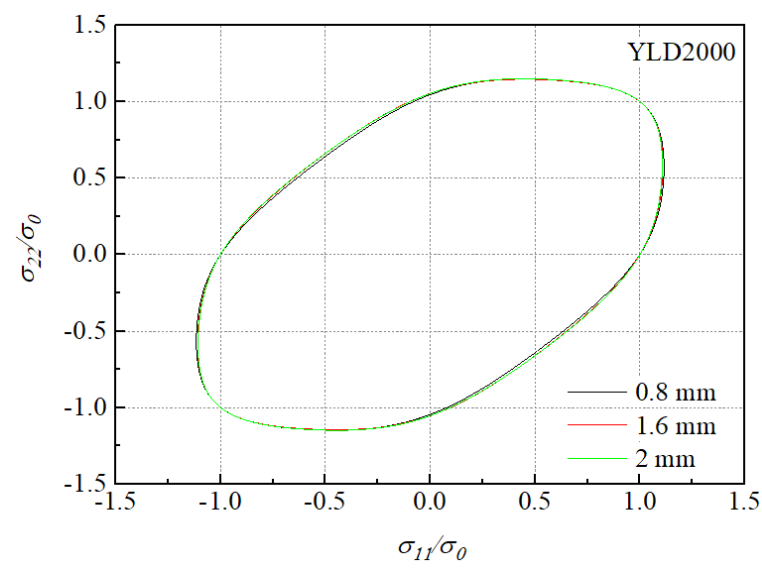

Fig. 8. The yield contours predicted with the YLD2000-2d for different thicknesses

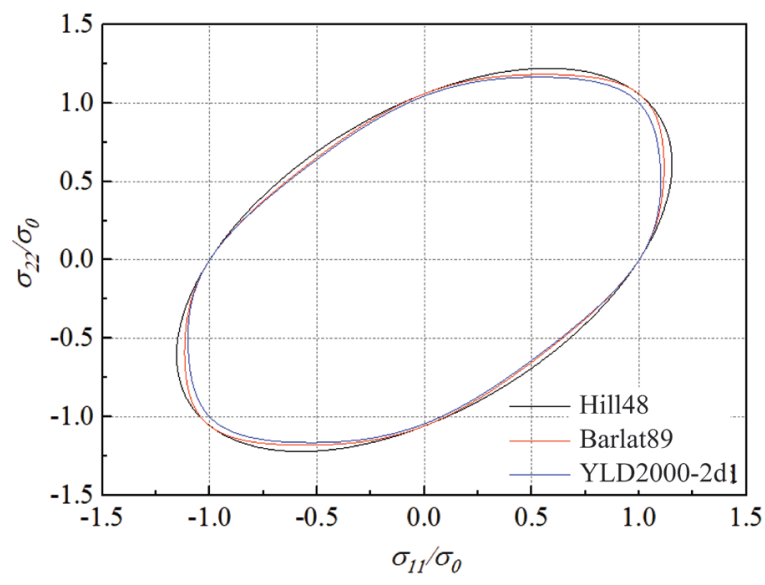

Fig. 9. Comparison of yield functions 

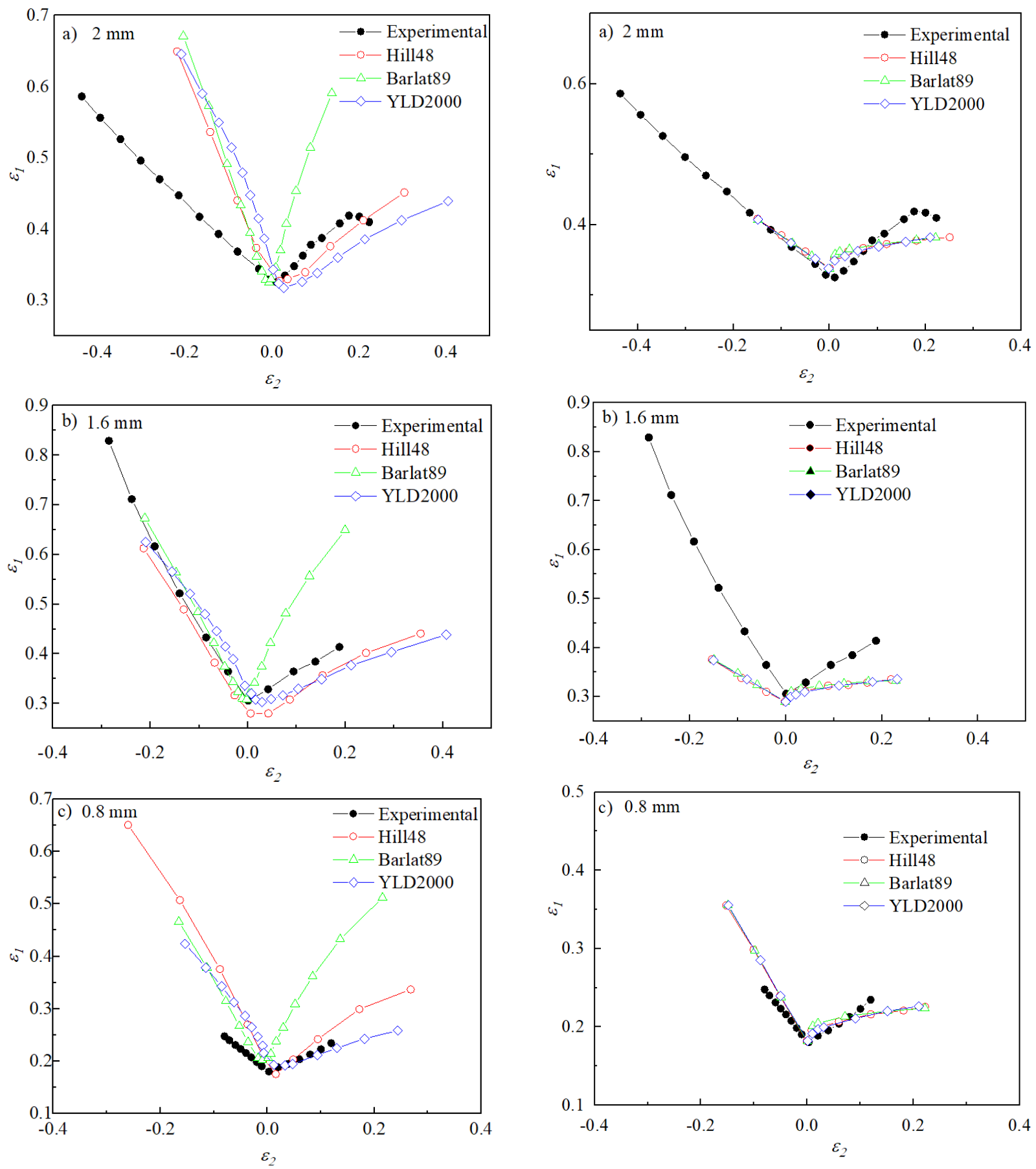

Fig. 10. FLD curves from the $M-K$ model and the yield criteria for thickness; a) $2 \mathrm{~mm}$, b) $1.6 \mathrm{~mm}$, and c) $0.8 \mathrm{~mm}$

Fig. 11. FLD curves from the proposed model and the yield criteria for thickness; a) $2 \mathrm{~mm}$, b) $1.6 \mathrm{~mm}$, and c) $0.8 \mathrm{~mm}$

both models. Finally, the following conclusions were drawn:

- The estimated yield locus, the anisotropy coefficients, and the normalized yield strengths for DP600 fit well with the experimental data for the YLD2000-2d criterion. It can simulate 
parameters gives more nonlinearity to be able to represent the cases with complex loading, such as biaxial deformation for which material anisotropy plays a significant role on the formability and defect occurrences. Therefore, this criterion is suitable for sheet metal deformation simulations.
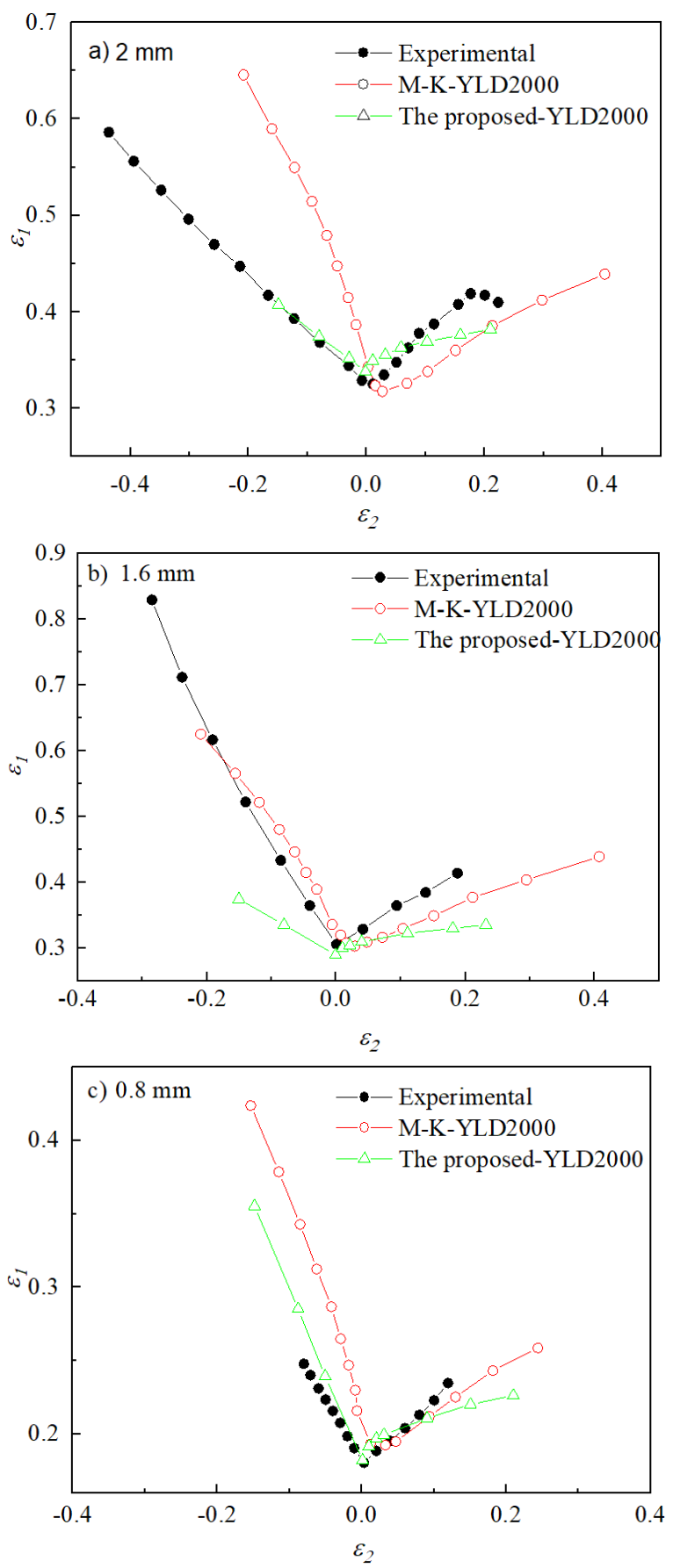

Fig. 12. Comparison of the $M K$ and the proposed criteria for thickness; a) $2 \mathrm{~mm}$, b) $1.6 \mathrm{~mm}$, and c) $0.8 \mathrm{~mm}$
- The YLD2000-2d represents the most suitable curve in the positive deformation zone of FLDs, which means that it can be preferred for failure predictions of DP600 sheet metals. Its consistency continues for all thickness for the sheet.

- When the sheet thickness is $2 \mathrm{~mm}$, the Hill48 and the Barlat 89 criteria show bigger deviation from the experimental curve. Thus, both criteria were consistent up to $2 \mathrm{~mm}$ sheet thickness.

- The proposed model combined with the YLD2000-2d gives the most precise failure predictions for DP600 sheet steels.

- Within the scope of this study, a failure criterion was presented for sheet metals. Further work for this research should be evaluated for the sheets thicker than $2 \mathrm{~mm}$ of DP600 and other AHSSs.

\section{REFERENCES}

[1] Kleiner, M., Chatti, S., Klaus, A. (2006). Metal forming techniques for lightweight construction. Journal of Materials Processing Technology, vol. 177, no. 1-3, p. 2-7, DOI:10.1016/J.jmatprotec.2006.04.085.

[2] Kleiner, M., Geiger, M., Klaus, A. (2003). Manufacturing of lightweight components by metal forming. Cirp AnnalsManufacturing Technology, vol. 52, no. 2, p. 521-542, DOl:10.1016/S0007-8506(07)60202-9.

[3] Neugebauer, R., Altan, T., Geiger, M., Kleiner, M., Sterzing, A. (2006). Sheet metal forming at elevated temperatures. Cirp Annals-Manufacturing Technology, vol. 55, no. 2, p. 793-816, DOl:10.1016/j.cirp.2006.10.008.

[4] Huh, H., Kim, S.B., Song, J.H., Lim, J.H. (2008). Dynamic tensile characteristics of trip-type and dp-type steel sheets for an auto-body. International Journal of Mechanical Sciences, vol. 50, no. 5, p. 918-931, D0l:10.1016/j.ijmecsci.2007.09.004.

[5] Golovashchenko, S.F., Gillard, A.J., Mamutov, A.V. (2013). Formability of dual phase steels in electrohydraulic forming. Journal of Materials Processing Technology, vol. 213, no. 7, p. 1191-1212, D0I:10.1016/j.jmatprotec.2013.01.026.

[6] Kamal Bashah, N.A., Muhamad, N., Md Deros, B., Zakaria, A., Ashari, S., Mobin, A., Mohd Abdul Lazat, M.S. (2013). Multiregression modeling for springback effect on automotive body in white stamped parts. Materials \& Design, vol. 46, no. 0, p. 175-190, D0I:10.1016/j.matdes.2012.10.006.

[7] Dong, D., Liu, Y., Yang, Y., Li, J., Ma, M., Jiang, T. (2014). Microstructure and dynamic tensile behavior of dp600 dual phase steel joint by laser welding. Materials Science and Engineering A, vol. 594, p. 17-25, D0l:10.1016/j. msea.2013.11.047.

[8] Farabi, N., Chen, D.L., Li, J., Zhou, Y., Dong, S.J. (2010). Microstructure and mechanical properties of laser welded dp600 steel joints. Materials Science and Engineering, vol. 527, no. 4-5, p. 1215-1222, D0l:10.1016/j.msea.2009.09.051.

[9] Nasser, A., Yadav, A., Pathak, P., Altan, T. (2010). Determination of the flow stress of five ahss sheet materials ( $d p 600$, dp 780, dp 780-cr, dp 780-hy and trip 780) using the uniaxial tensile 
and the biaxial viscous pressure bulge (VPB) tests. Journal of Materials Processing Technology, vol. 210, no. 3, p. 429-436, DOI:10.1016/J.jmatprotec.2009.10.003.

[10] Pepelnjak, T., Kayhan, E., Kaftanoglu, B. (2019). Analysis of non-isothermal warm deep drawing of dual-phase dp600 steel. International Journal of Material Forming, vol. 12, no. 2, p. 223-240, D0I:10.1007/s12289-018-1400-0.

[11] Ramazani, A., Abbasi, M., Prahl, U., Bleck, W. (2012). Failure analysis of dp600 steel during the cross-die test. Computational Materials Science, vol. 64, no. 0, p. 101-105, D0l:10.1016/j.commatsci.2012.01.031.

[12] Keeler, S.P. (1994). Application and forming of higher strength steel. Journal of Materials Processing Technology, vol. 46, no. 3-4, p. 443-454, D0l:10.1016/0924-0136(94)90127-9.

[13] Keeler, S., P., Backhofen, W., A. (1964). Plastic instability and fracture in sheet stretched over rigid punches. ASM Trans. Quart, vol. 56, p. 25-48.

[14] Goodwin, G.M. (1968). Application of strain analysis to sheet metal forming in the press shop. SAE paper, vol. 680093, DOl:10.4271/680093.

[15] Aleksandrović, S., Stefanović, M., Adamović, D., Lazić, V. (2009). Variation of normal anisotropy ratio " $r$ " during plastic forming. Strojniški vestnik - Journal of Mechanical Engineering, vol. 55, no. 6, p. 392-399.

[16] Satošek, R., Valeš, M., Pepelnjak, T. (2019). Study of influential parameters of the sphere indentation used for the control function of material properties in forming operations. Strojniški vestnik - Journal of Mechanical Engineering, vol. 65, no. 10, p. 585-598, D0I:10.5545/sv-jme.2019.6312.

[17] Starman, B., Vrh, M., Halilovič, M., Štok, B. (2014). Advanced modelling of sheet metal forming considering anisotropy and young's modulus evolution. Strojniški vestnik - Journal of Mechanical Engineering, vol. 60, no. 2, p. 84-92 Dol:10.5545/ sv-jme.2013.1349.

[18] Swift, H.W. (1952). Plastic instability under plane stress. Journal of the Mechanics and Physics of Solids, vol. 1, no. 1, p. 1-18, DOI:10.1016/0022-5096(52)90002-1.

[19] Hill, R. (1952). On discontinuous plastic states, with special reference to localized necking in thin sheets. Journal of the Mechanics and Physics of Solids, vol. 1, p. 19-30, DOI:10.1016/0022-5096(52)90003-3.

[20] Petek, A., Pepelnjak, T., Kuzman, K. (2005). An improved method for determining a forming limit diagram in the digital environment. Strojniški vestnik - Journal of Mechanical Engineering, vol. 51, no. 6, p. 16330-345.

[21] Marciniak, Z., Kuczyński, K. (1967). Limit strains in the processes of stretch-forming sheet metal. International Journal of Mechanical Sciences, vol. 9, no. 9, p. 609-620, DOI:10.1016/0020-7403(67)90066-5.

[22] Banabic, D., Aretz, H., Paraianu, L., Jurco, P. (2005). Application of various fld modelling approaches. Modelling and Simulation in Materials Science and Engineering, vol. 13, no. 5, p. 759-769, Dol:10.1088/0965-0393/13/5/009.

[23] Hora, P., Tong, L., Reissner, J. (1996). A prediction method for ductile sheet metal failure in fe-simulation. Numisheet ' $96, \mathrm{p}$. 252-256.

[24] Banabic, D., Aretz, H., Comsa, D.S., Paraianu, L. (2005). An improved analytical description of orthotropy in metallic sheets. International Journal of Plasticity, vol. 21, no. 3, p. 493-512, D0I:10.1016/j.ijplas.2004.04.003.

[25] Vrh, M., Halilovič, M., Starman, B., Štok, B., Comsa, D.-S., Banabic, D. (2014). Capability of the bbc2008 yield criterion in predicting the earing profile in cup deep drawing simulations. European Journal of Mechanics - A/Solids, vol. 45, p. 59-74, D0I:10.1016/j.euromechsol.2013.11.013.

[26] Arrieux, R., Brunet, M., Vacher, P., Nhat, T.N. (1996). A method to predict the onset of necking in numerical simulation of deep drawing operations. CIRP Annals, vol. 45, no. 1, p. 255258, DOI:10.1016/S0007-8506(07)63058-3.

[27] Slota, J., Spisak, E. (2005). Comparison of the forming-limit diagram (FLD) models for drawing quality (DQ) steel sheets. Metalurgija, vol. 44, no. 4, p. 249-253.

[28] ASTM E8 / E8M (2004). Standard test methods for tension testing of metallic materials. American Society for Testing and Materials, vol. E8, West Conshohocken.

[29] Hollomon, J.H. (1945). Tensile deformation. Transactions of the Metallurgical Society of AIME, vol. 162, p. 268-290.

[30] Ozturk, F., Lee, D. (2005). Experimental and numerical analysis of out-of-plane formability test. Journal of Materials Processing Technology, vol. 170, no. 1-2, p. 247-253, DOI:10.1016/J.jmatprotec.2005.05.010.

[31] Buranathiti, T. (2007). Simulation and benchmark of an automotive underbody cross member panel. ASIMMOD2007, p. 107-113.

[32] Tigrinho, L.M.V., Filho, R.A.C., Neto, R.d.C.B., Lajarin, S.F., Marcondes, P.V.P. (2011). Forming analyses of dp600 steel using different blank-holder pressures. 21st Brazilian Congress of Mechanical Engineering, p. 112-122.

[33] Hill, R. (1948). A theory of the yielding and plastic flow of anisotropic metals. Proceedings of the Royal Society A vol. 193, p. 281-297, D0l:10.1098/rspa.1948.0045.

[34] Barlat, F., Lian, K. (1989). Plastic behavior and stretchability of sheet metals. Part i: A yield function for orthotropic sheets under plane stress conditions. International Journal of Plasticity, vol. 5, no. 1, p. 51-66, Dol:10.1016/07496419(89)90019-3.

[35] Barlat, F., Brem, J.C., Yoon, J.W., Chung, K., Dick, R.E., Lege, D.J., Pourgoghrat, F., Choi, S.H., Chu, E. (2003). Plane stress yield function for aluminum alloy sheets - part 1: Theory. International Journal of Plasticity, vol. 19, no. 9, p. 12971319, Dol:10.1016/s0749-6419(02)00019-0.

[36] Maček, A., Starman, B., Mole, N., Halilovič, M. (2020). Calibration of advanced yield criteria using uniaxial and heterogeneous tensile test data. Metals, vol. 10, p. 542, DOI:10.3390/met10040542.

[37] Hosford, W.F. (1972). A generalized isotropic yield criterion. Journal of Applied Mechanics, vol. 39, no. 2, p. 607-609, DOI:10.1115/1.3422732.

[38] Butuc, M.C., Banabic, D., da Rocha, A.B., Gracio, J.J., Duarte, J.F., Jurco, P., Comsa, D.S. (2002). The performance of YLD96 and bbc2000 yield functions in forming limit prediction. Journal of Materials Processing Technology, vol. 125, p. 281286, DOI:10.1016/s0924-0136(02)00399-0.

[39] Butuc, M.C., da Rocha, A.B., Gracio, J.J., Duarte, J.F. (2002). A more general model for forming limit diagrams prediction. 
Journal of Materials Processing Technology, vol. 125-126, p. 213-218, D0I:10.1016/S0924-0136(02)00315-1

[40] Cao, J., Yao, H., Karafillis, A., Boyce, M.C. (2000). Prediction of localized thinning in sheet metal using a general anisotropic yield criterion. International Journal of Plasticity, vol. 16, no. 9, p. 1105-1129, Dol:10.1016/s0749-6419(99)00091-1.

[41] Yao, H., Cao, J. (2002). Prediction of forming limit curves using an anisotropic yield function with prestrain induced backstress. International Journal of Plasticity, vol. 18, no. 8, p. 1013-1038, D0l:10.1016/S0749-6419(01)00022-5.

[42] Grobbelaar, M. (2020). Lifting plate incompressibility condition for stability of a magnetoelastic mindlin-timoshenko model. Applied Mathematics Letters, vol. 102, p. 106084, DOI:10.1016/j.aml.2019.106084.

[43] Kılıç, S., Öztürk, F. (2016). Comparison of commercial twip900 and dp600 high strength steels in the automotive industry. Gazi University Journal of Engineering and Architecture, vol. 31, no. 3, p. 567-578, D0l:10.17341/gummfd.81389.

[44] Zillmann, B., Wagner, M.F.X., Schmaltz, S., Schmidl, E., Lampke, T., Willner, K., Halle, T. (2015). In-plane biaxial compression and tension testing of thin sheet materials.
International Journal of Solids and Structures, vol. 66, p. 111 120, DOI:10.1016/j.ijsolstr.2015.03.031.

[45] Takuda, H., Mori, K., Takakura, N., Yamaguchi, K. (2000). Finite element analysis of limit strains in biaxial stretching of sheet metals allowing for ductile fracture. International Journal of Mechanical Sciences, vol. 42, no. 4, p. 785-798, DOI:10.1016/S0020-7403(99)00018-1.

[46] Xu, L., Barlat, F., Lee, M.-G. (2012). Hole expansion of twinning induced plasticity steel. Scripta Materialia, vol. 66, no. 12, p. 1012-1017, D0l:10.1016/j.scriptamat.2012.01.062.

[47] Hollomon, J.R. (1945). Tensile deformation. Transaction of AIME, vol. 162, no. 1, p. 268-277.

[48] Kılıç, S., Toros, S., Kacar, I., Öztürk, F. (2018). Lüy, Ö.T.M., Çam, E., Barışçı, N., Demirbaş, M.D., Güçyetmez, M. (eds.). Scientific and Professional Studies-Engineering and Technology in the World of the Future, Ekin press, Bursa, p. 271-290.

[49] Banabic, D., Carleer, B., Comsa, D.-S., Kam, E., Krasovskyy, A., Mattiasson, K., Sester, M., Sigvant, M., Zhang, X. (2010). Sheet Metal Forming Processes: Constitutive Modelling and Numerical Simulation. Springer-Verlag Berlin Heidelberg. 